\title{
Anticorpos anti-Leptospira em pacientes de Mato Grosso do Sul com suspeita clínica de dengue ou hepatite viral
}

\author{
Anti-Leptospira antibodies in patients in the State of Mato Grosso do Sul \\ with clinical suspicion of dengue or viral hepatitis
}

\author{
Alda Izabel de Souza ${ }^{1}$, Joseli Maria da Rocha Nogueira ${ }^{2}$ e Martha Maria Pereira ${ }^{3}$
}

\begin{abstract}
RESUMO
Considerando a carência de dados clínicos e epidemiológicos da leptospirose humana no Estado de Mato Grosso do Sul e a possibilidade de confusão com outras doenças, soros de pacientes com suspeita clínica inicial de dengue e hepatite viral, porém, sem confirmação laboratorial, foram examinados, através de soroaglutinação microscópica para leptospirose. Os índices de sororreagentes nas amostras com suspeita clínica de dengue e hepatite viral foram, respectivamente, 15,9\% e 9\%. A maior ocorrência foi para o sorovar hurstbridge (70,4\%) e o maior título para o sorovar canicola (1:51.200). Não se observou associação entre positividade e sexo, idade ou ocupação dos pacientes. O estudo demonstrou que, embora as atuais notificações de casos de leptospirose em Mato Grosso do Sul sejam irrisórias, a prevalência de anticorpos foi elevada nos grupos investigados e, portanto, a hipótese de subnotificação de casos de leptospirose humana em Mato Grosso do Sul e dificuldades no diagnóstico diferencial com dengue e hepatite viral devem ser consideradas.
\end{abstract}

Palavras-chaves: Leptospirose. Dengue. Hepatite viral. Soroaglutinação microscópica.

\section{ABSTRACT}

In view of the lack of clinical and epidemiological data on human leptospirosis in the State of Mato Grosso do Sul, and the possibility of confounding it with other diseases, sera from patients with a preliminary clinical suspicion of dengue or viral hepatitis but without laboratory confirmation were examined by means of microscopic seroagglutination techniques for leptospirosis. The seroreactivity rates among the samples with clinically suspected dengue or viral hepatitis were $15.9 \%$ and $9 \%$. The most frequent serovar was Hurstbridge (70.4\%) and the serovar with the highest titer was Canicola (1:51,200). No association was found between seropositivity and the patients' sex, age or occupation. This study demonstrated that, although the present notifications of leptospirosis cases in Mato Grosso do Sul are negligible, the prevalence of antibodies was high in the groups investigated. Therefore, the hypothesis that there is undernotification of human leptospirosis cases in this State and difficulties in the differential diagnosis between dengue and viral hepatitis should be considered.

Key-words: Leptospirosis. Dengue. Viral hepatitis. Microscopic seroagglutination.

A leptospirose humana é uma enfermidade febril aguda, cosmopolita, causada por bactérias do gênero Leptospira, que infectam, além do homem, animais domésticos e silvestres, os quais podem participar da cadeia epidemiológica como portadores assintomáticos e reservatórios. A enfermidade se caracteriza, epidemiologicamente, como uma zoonose de grande importância em saúde pública e, tanto no homem, como nos animais, as manifestações clínicas variam muito em tipo e gravidade ${ }^{8}$.

Vários trabalhos têm demonstrado confusões diagnósticas entre leptospirose, dengue e hepatite viral, tanto pela similaridade do quadro clínico, quanto pela superposição da sazonalidade ${ }^{12131421}$, constituindo, portanto, um problema de importância para a instituição do tratamento adequado ao paciente.

O Estado de Mato Grosso do Sul apresenta características ambientais bastante específicas, tais como altos índices pluviométricos, temperaturas elevadas durante vários meses do ano e, ainda, a presença de reservatórios domésticos e silvestres que favorecem a disseminação de Leptospira. Todavia, não se conhece a magnitude desse problema na população humana da região e os casos de leptospirose registrados se referem a quadros com manifestações clínicas características da Síndrome de Weil.

\footnotetext{
1. Universidade para o Desenvolvimento do Estado e da Região do Pantanal, Campo Grande, MS. 2. Instituto Oswaldo Cruz- Fundação Oswaldo Cruz- Rio de Janeiro, RJ.

3. Centro de Referência Nacional para Leptospirose, Instituto Oswaldo Cruz, Rio de Janeiro, RJ.

Endereço para correspondência: Dr ${ }^{a}$ Alda Izabel de Souza. Trav. Nestor Moreira 38, Bairro São Bento,79004-100 Campo Grande, MS.

Tel: 556799836502

e-mail: aldaizabel@hotmail.com

Recebido em: 20/01/2007

Aceito em: 23/05/2007
} 
De acordo com o Sistema de Informação de Agravos de Notificação (SINAN) ${ }^{15}$ no ano de 2001, apenas um caso de leptospirose foi notificado no Estado, entretanto, 2.885 casos suspeitos de dengue não foram confirmado laboratorialmente.

Portanto, este trabalho teve como objetivo identificar a ocorrência de leptospirose através da avaliação da presença de anticorpos antiLeptospira em pacientes com suspeita clínica inicial de dengue e de hepatite viral, cujos exames específicos afastaram esses diagnósticos.

\section{MATERIAL E MÉTODOS}

0 Estado de Mato Grosso do Sul, localizado na região Centro Oeste, possui uma população 1.995 .578 habitantes, o que representa 1,2\% da população brasileira. Apresenta uma topografia plana, embora com variações altimétricas originando paisagens distintas, podendo-se identificar, por períodos variáveis, áreas sujeitas à inundações ou oscilações do lençol freático próximo à superfície; localizando-se em área de transição climática implica contrastes térmicos e variações de precipitação pluviométrica anual, com regiões que podem atingir excedentes hídricos durante 8 meses por ano $0^{422}$.

Em virtude da escassez de dados epidemiológicos sobre a leptospirose no estado e a hipótese de que muitos casos poderiam estar sendo confundidos com outras doenças, levou-se em conta, para a escolha da população a ser estudada, os critérios de similaridade de sinais clínicos e eventuais coincidências em relação à sazonalidade e distribuição geográfica de duas doenças que devem ser incluídas no diagnóstico diferencial da leptospirose, como dengue e hepatite viral.

Foram utilizados soros enviados ao Laboratório Central de Mato Grosso do Sul (LACEN), no período de dezembro 2000 a março de 2001, testados pelo Mac ELISA para dengue, com kit comercial fornecido pelo Instituto Evandro Chagas, Belém/PA, ou testados para hepatites A, B e ou C, utilizando kit comercial da Organon do Brasil ${ }^{\oplus}$, com resultados negativos.

A partir de dados obtidos de um projeto piloto, que demonstrou uma prevalência de anticorpos inicial de 14,1\% para Leptospira, nessa população, definiu-se a amostragem do estudo, considerando um intervalo de confiança de 0,03, o que resultou um total de 439 amostras de soro, as quais foram colhidas e armazenadas sob congelamento a $-20^{\circ} \mathrm{C}$ até 0 momento dos testes laboratoriais.

Os soros não reagentes às provas sorológicas para dengue e hepatite viral foram submetidos ao teste de soroaglutinação microscópica (SAM), segundo Faine ${ }^{7}$, no Centro de Referência Nacional para Leptospirose, Laboratório de Zoonoses Bacterianas, do Departamento de Bacteriologia do Instituto Oswaldo Cruz, Rio de Janeiro. Foram utilizados 18 sorovares cultivados em meio de Ellinghausen-McCullough-Johnson-Harris (ЕMJH), os quais representavam 16 sorogrupos. De acordo com os padrões de reação, os soros foram classificados em três categorias $^{18}$ : 1) Sem co-aglutinação, compreendendo os soros que reagiram com apenas um sorovar. 2) Com co-aglutinação e predomínio de título, englobando os soros que reagiram com mais de um sorovar, apresentando, entretanto, títulos mais altos para um deles. 3) Com co-aglutinação sem predomínio de título, incluindo os soros que reagiram com mais de um sorovar, em títulos iguais.

Os dados referentes a procedência, sexo, idade e atividade profissional dos pacientes, foram obtidos através das fichas de identificação que acompanhavam as amostras enviadas ao LACEN. A atividade profissional foi classificada de acordo com a Classificação Brasileira de Ocupações do Ministério do Trabalho e Emprego do ano de $1999^{16}$ e a procedência por região foi distribuída segundo a Fundação Instituto Brasileiro de Geografia e Estatística (IBGE) ${ }^{10}$ que divide o estado em 4 mesorregiões: a dos Pantanais Sul Matogrossense, a do Centro-Norte, a Leste e Sudoeste.

Como as amostras não foram submetidas a pareamento, admitiu-se como confirmatório para leptospirose o título de anticorpos igual ou maior que 1:800 de acordo com orientação do Ministério da Saúde ${ }^{11}$.

Em virtude da impossibilidade de realizar a investigação epidemiológica de todos os pacientes estudados, foi adotada a busca ativa de informações relativas aos casos que apresentaram sorologia positiva. Os pacientes localizados foram submetidos à entrevista utilizando a ficha individual de investigação epidemiológica para leptospirose da Fundação Nacional de Saúde do Ministério da Saúde.

Todos os dados obtidos foram armazenados no programa estatístico EPI-INFO, versão 6,0, o qual possibilitou a tabulação dos mesmos para a realização das análises.

\section{RESULTADOS}

Das 215 amostras com suspeita inicial de dengue na SAM, 34 $(15,9 \%)$ foram positivas para Leptospira. Destas, 8 apresentaram título maior ou igual a 1:800.

Das 224 amostras com suspeita, mas sem confirmação diagnóstica de hepatite viral, 20 apresentaram índices de positividade para leptospirose, sendo que, deste grupo, 5 casos poderiam ter a doença confirmada pela verificação de título igual ou maior a 1:800, considerando os critérios já referidos ${ }^{11}$.

Evidenciou-se uma diferença estatística significativa $\left(\chi^{2}=4,32\right.$ $\mathrm{p}=0,04)$ e um coeficiente de contingência de Pearson de 0,10 entre os dois estratos populacionais testados.

A Tabela 1 mostra que $42(75,9 \%)$ soros reagiram a títulos baixos (iguais ou menores que 1:400), mas $13(24,1 \%)$ reagiram com títulos considerados altos (iguais ou maiores que 1:800); estes, segundo os critérios do Ministério da Saúde ${ }^{11}$ seriam diagnosticados como leptospirose, tendo em vista os títulos que variaram de 1:800 a 51.200.

Os resultados obtidos mostram reações positivas e cruzadas com 11 entre os 18 sorovares testados e predominância 
Tabela 1 - Distribuição dos 54 soros reagentes frente os antígenos utilizados na reação de soroaglutinação microscópica de pacientes negativos para dengue ou bepatite viral.

\begin{tabular}{|c|c|c|c|c|c|c|c|c|c|c|c|}
\hline \multirow[b]{2}{*}{ Padrões de reação } & \multirow[b]{2}{*}{ Sorovares } & \multicolumn{10}{|c|}{ Títulos } \\
\hline & & 100 & 200 & 400 & 800 & 1.600 & 3.200 & 6.400 & 12.800 & 25.600 & 51.200 \\
\hline & copenhageni & 1 & & & & & & & & & \\
\hline & grippotyphosa & & & 1 & & & & & & & \\
\hline & australis & 2 & & & & & & & & & \\
\hline & bataviae & & & & 1 & & & & & & \\
\hline \multirow[t]{7}{*}{ Sem co-aglutinação } & bardjo & & 1 & & 1 & & & & & & \\
\hline & tarassovi & & 2 & & & & & & & & \\
\hline & cuica & 1 & & & & & & & & & \\
\hline & burstbridge & 12 & 5 & 5 & & & & & & & \\
\hline & icterohaemorrhagiae & & & & 1 & & & & & & \\
\hline & grippotyphosa & & & 1 & & & & & & & \\
\hline & panama & & & 1 & & & & & & & \\
\hline \multirow{6}{*}{$\begin{array}{l}\text { Co-aglutinação com } \\
\text { predomínio de título }\end{array}$} & canicola & & & & & & 1 & & & & 1 \\
\hline & australis & & & 1 & & & & & & & \\
\hline & tarassovi & & 1 & 1 & & & & & & & \\
\hline & bardjo & & & & 2 & & & & & & \\
\hline & burstbridge & & 1 & 2 & 2 & 1 & 1 & & & & \\
\hline & icterohaemorrhagiae/austral & alis & 1 & & & & & & & & \\
\hline \multirow{4}{*}{$\begin{array}{l}\text { Co-aglutinação sem } \\
\text { predomínio de título }\end{array}$} & copenhageni/australis & & 1 & & & & & & & & \\
\hline & grippotyphosa/hurstbridge & & & 1 & & & & & & & \\
\hline & canicola/hurstbridge & & & & 1 & & & & & & \\
\hline & tarassovi/hurstbridge & & & & 1 & & & & & & \\
\hline
\end{tabular}

do sorovar hurstbridge. Foram ainda detectadas respostas positivas, seguindo-se em ordem decrescente, para os sorovares gryppotyphosa, australis, tarassovi, icterobaemorrhagiae, cuica, panama, hardjo, canicola, copenhageni, bataviae, javanica e shermani (Tabela 1).

Considerando as mesorregiões do estado, a frequiência de positividade para leptospirose revelou um índice mais alto de soros reagentes nas mesorregiões dos Pantanais Sul Matogrossense e Sudoeste com 19,2\% (05/26) e 15,2 (18/118), respectivamente, seguidos pelas mesorregiões Centro-Norte com 11\% (26/236) e Leste com 8,5\% (5/59), sem demonstrar diferenças estatísticas $(\chi 2=2,04 \mathrm{p}=0,56)$ significativas entre elas.

De 224 soros de indivíduos do sexo masculino, 34 (15,2\%) foram reagentes e das 215 (48,9\%) do sexo feminino, 20 (9,3\%) foram positivas frente aos antígenos utilizados. Porém, as análises estatísticas não demonstraram diferenças significativas entre sexo $(\chi 2=3,51 \mathrm{p}=0,06)$.

A Tabela 2 mostra a positividade em relação à ocupação. Embora a diversidade de atividades listadas, através das fichas de identificação que acompanhavam as amostras, tenha impossibilitado uma tabulação mais simplificada desta variável, observam-se índices de soroaglutinação em todos os grupos de atividade.

Em relação aos fatores de risco investigados, observou-se que $73,7 \%$ (14/19) dos entrevistados relataram a presença de roedores no peridomicílio e 52,6\% (10/19) declararam contato com lixo, entulhos ou residência em áreas com coleta de lixo inadequada. Outros fatores, tais como: contato com enxurrada
(9/19), presença de terreno baldio nas imediações do domicilio (8/19), imersão em água de rio ou córrego (7/19), contato com lavoura (5/19) e criação de animais domésticos (5/19) também foram relatados.

Tabela 2 - Presença de respostas positivas e negativas na soroaglutinação microscópica em relação a principal ocupação ou atividade dos pacientes testados.

\begin{tabular}{|c|c|c|c|c|c|}
\hline \multirow[t]{2}{*}{ Grupo/ocupação } & \multicolumn{2}{|c|}{ Positivo } & \multicolumn{2}{|c|}{ Negativo } & \multirow[b]{2}{*}{ Total } \\
\hline & $\mathrm{n}^{0}$ & $\%$ & $\mathrm{n}^{0}$ & $\%$ & \\
\hline Crianças $<$ de 5 anos & 1 & 04,2 & 24 & 95,8 & 25 \\
\hline $\begin{array}{l}\text { Estudantes, trabalhadores } \\
\text { das profissões científicas, } \\
\text { administrativos, funcionários }\end{array}$ & & & & & \\
\hline públicos, do comércio e assemelhados & 11 & 09,5 & 116 & 90,5 & 127 \\
\hline $\begin{array}{l}\text { Trabalhadores de serviços de turismo, } \\
\text { embelezamento, hospedagem, serventia, } \\
\text { higiene, segurança e assemelhados }\end{array}$ & 11 & 10,0 & 110 & 90,0 & 121 \\
\hline $\begin{array}{l}\text { Trabalhadores agropecuários, } \\
\text { florestais, da pesca e assemelhados }\end{array}$ & 12 & 32,4 & 37 & 67,6 & 49 \\
\hline $\begin{array}{l}\text { Trabalhadores da produção industrial, } \\
\text { operadores de máquinas, condutores }\end{array}$ & & & & & \\
\hline de veículo e assemelhados & 9 & 24,3 & 37 & 75,7 & 46 \\
\hline Aposentados & 3 & 09,4 & 32 & 90,6 & 35 \\
\hline Ocupação não declarada & 7 & 08,4 & 83 & 91,6 & 90 \\
\hline Total & 54 & 12,3 & 385 & 87,7 & $\begin{array}{c}439 \\
(100,0 \%)\end{array}$ \\
\hline
\end{tabular}




\section{DISCUSSÃo}

Essa investigação fundamentou-se na hipótese de que, no Mato Grosso do Sul, uma fração dos casos não confirmados de dengue e hepatite viral poderiam ser diagnosticados como leptospirose caso fossem realizados os testes específicos, uma vez que embora a região possua características peculiares para a disseminação do agente etiológico, o número de casos notificados de leptospirose no estado tem sido irrisório.

No presente trabalho, os índices de positividade para leptospirose em 15,9\% das amostras não confirmados para dengue e em $9 \%$ das não confirmadas para hepatite viral, embora não submetidos a pareamento de amostras, permitem sugerir uma infecção recente pela bactéria. Tal afirmação está de acordo com a orientação do Ministério da Saúde ${ }^{11}$ que admite como confirmatório os soros não pareados com título igual ou superior a 1:800.

A detecção de leptospirose em pacientes suspeitos de dengue, mas sem confirmação, revelaram índices de positividade para Leptospira que variaram de 6,9\% a 83\% em diferentes regiões, e reconhecem a confusão diagnóstica, que tem como consequiência o falso aumento do índice de letalidade associado ao dengue e, obviamente, a subnotificação da leptospirose nesses $\operatorname{casos}^{1317}{ }^{21}$.

No Vietnã, durante estudos realizados com 70 pacientes que apresentaram quadro de icterícia aguda, porém, negativos para hepatite viral do tipo A e ou B, utilizando o método ELISA, Bounlu e cols ${ }^{1}$ observaram $21 \%$ de infecção leptospírica, indicando que os casos de hepatite viral foram superestimados devido a ausência de métodos laboratoriais que fizessem a diferenciação ou identificação de outras doenças.

A observação de que o número de soros reagentes para leptospira nos pacientes com suspeita inicial de dengue difere estatisticamente do grupo com suspeita de hepatite viral, sugere que muitos casos de leptospirose no Mato Grosso do Sul podem apresentar manifestações mais brandas da doença.

Esses casos clínicos não diagnosticados e, portanto, não notificados, evidenciam o desconhecimento da importância da leptospirose no estado, razão pela qual muitos profissionais de saúde, talvez, não a incluam em seu diagnóstico diferencial.

A predominância do sorovar hurstbridge, difere de outras investigações que identificaram um predomínio do sorogrupo Icterohaemorrhagiae sobre as demais variedades sorológicas, tanto nos casos de doença comprovada laboratorialmente quanto em inquéritos epidemiológicos ${ }^{12} 202324$ A variabilidade de reações com diferentes sorovares e cepas observadas permite supor a circulação desses antígenos no Mato Grosso do Sul. Salienta-se, no entanto, as reações cruzadas entre os diversos sorovares e as reações paradoxais, que podem ocorrer na fase inicial da infecção. Sem dúvida que, nesta fase, será fundamental o isolamento e identificação da bactéria para confirmação do sorovar envolvido ou pelo menos o pareamento da amostra.

Quando se avalia estatisticamente os dados de positividade em relação ao sexo (Tabela 1), observa-se que não houve variação significativa. Na literatura, o sexo masculino aparece como mais prevalente, e assinala-se que essa peculiaridade decorre das atividades profissionais exercidas, expondo-os mais em locais potencialmente contaminados ${ }^{6}$. Já em condições sanitárias básicas deficientes associadas aos fatores ambientais propícios para a propagação da Leptospira, não se observam diferença estatística entre os sexos ${ }^{17}$. No presente estudo, como não houve uma seleção das amostras por atividade de risco, admite-se que ambos os sexos, sob o ponto de vista estatístico $(\chi 2=3,51$ $\mathrm{p}=0,06)$, tiveram a mesma probabilidade de se contaminar e se coaduna com Faine ${ }^{7}$ de que a infecção leptospírica não difere entre os sexos, quando são igualmente expostos.

A idéia de que a leptospirose constitui uma entidade nosológica que guarda estreita relação com certas profissões exercidas pelos indivíduos é bastante antiga e tem norteado a grande maioria dos estudos 5 . Tal idéia pode ser confirmada através dos inquéritos epidemiológicos direcionados para grupos profissionais supostamente expostos ao contato com a Leptospira ${ }^{324}$.

A análise dos índices de positividade nos grupos estudados, permite concluir que toda a população está sob risco de contato com Leptospira, independentemente do tipo de atividade laborativa, corroborando com vários trabalhos ${ }^{912} 212$.

Sabendo-se que na epidemiologia da leptospirose estão envolvidos fatores de ordem sócio-econômica, bem como, condições ambientais que favorecem a sobrevivência do agente na natureza, destaca-se no relato dos indivíduos entrevistados, a presença de roedores, contatos com lixo, entulhos e enxurrada ou enchente. Isto reforça a idéia de que a presença de ecossistemas degradados em áreas urbanas, caracterizados pelo empobrecimento da população e pela ausência de saneamento básico, pode proporcionar a instalação e manutenção de focos de leptospirose, permitindo a livre circulação de Leptospira e sua transmissão ao homem ${ }^{19}$.

A partir dos dados obtidos, que por sinal constituem 0 primeiro inquérito sobre a situação da leptospirose humana no Estado de Mato Grosso do Sul, admite-se a ocorrência de casos de leptospirose no Estado, não diagnosticados e, conseqüentemente, não notificados, devido a confusão com dengue ou hepatite viral.

Diante do cenário exposto, acrescido dos prejuízos econômicos advindos do absenteísmo, cuidados médicos e hospitalização, ressalta-se a necessidade de alerta aos profissionais de saúde, de que a leptospirose também é uma doença febril e que os testes laboratoriais para dengue, hepatite viral e leptospirose são fundamentais para o esclarecimento clínico e para as ações de vigilância epidemiológica.

\section{AGRADECIMENTOS}

Ao Dr. Ernesto Hofer da Fundação Oswaldo Cruz, Rio de Janeiro, pela importante ajuda na revisão do trabalho.

\section{REFERÊNCIAS}

1. Bounlu K, Insisiengmay S, Vanthanouvong K, Widjaja S, Iinuma K, Matsubayashi K, Laras K, Putri MP, Endy TP, Vaughn DW, Raengsakulrach B, Hyams KC, Hayden M, Scheffel C, Corwin AL. Acute jaundice in Vientiane, Lao People's Democratic Republic. Clinical Infectious Disease 27: 717-721, 1998. 
2. Bruce MG, Sanders EJ, Leake JAD, Zaidel 0, Bragg SL, Aye T, Shutt KA, Deseda CC, Rigau-Perez JG, Tappero JW, Perkins BA, Spiegel RA, Ashford DA. Leptospirosis among patients presenting with dengue-like illness in Puerto Rico. Acta Tropica 96; 36-46, 2005.

3. Cacchione RA, Cascelli ES, Martinez ES. Encuesta serológica sobre leptospirosis humana en Argentina. Revista da Associação Argentina de Microbiologia 7:21-27, 1975 .

4. Dias J. "Variação mesoclimática". Atlas Geográfico Digital de Mato Grosso do Sul. < http://www.uniderp.br/atlas/clima.htm> (10/10/00), 2000.

5. Duarte Filho J. Leptospirose - inquérito soroepidemiológico entre limpadores de canais urbanos, lavradores de arroz e trabalhadores de cana-de-açucar, em Sergipe, PhD Thesis, Escola Paulista de Medicina, São Paulo, 1991.

6. Everard COR, Bennett S, Edwards CN, Nicholson GD, Hassel TA, Carrington DG, Everard JD. An investigation of some risk factors for severe leptospirosis on Barbados. Journal of Tropical Medicine and Hygiene 95: 13-22, 1992.

7. Faine S. Guidelines for the control of leptospirosis. Word Health Organization, Offset Publ. n. 67. Geneva, 1982.

8. Farr RW. Leptospirosis. Clinical Infectious Disease 21: 1-8, 1995.

9. Figueiredo CM, Mourão AC, Oliveira MAA, Alves WR, Ooteman MC, Chamone CB, Koury MC. Leptospirose humana no município de Belo Horizonte, Minas Gerais, Brasil: uma abordagem geográfica. Revista da Sociedade Brasileira de Medicina Tropical 34: 331-338, 2001.

10. Fundação Instituto Brasileiro de Geografia e Estatística (IBGE). Divisão de Pesquisa no Estado de Mato Grosso do Sul/Composição das mesorregiões e microrregiões do Estado de Mato Grosso do Sul, 1998.

11. Fundação Nacional de Saúde-Centro Nacional de Epidemiologia/Coordenação de Controle de Zoonoses e Animais Peçonhentos. Manual de Leptospirose. Brasília, 1997.

12. Hernández MS, Sánchez RM, Fernández PEP, García IV, Fleites FB, Sibello AS. Brotes de leptospirosis humana en la provincia de Ciego de Ávila, Cuba. Revista da Sociedade Brasileira de Medicina Tropical 32:13-18, 1999.
13. Ko A, Reis MG, Dourado CMR, Johnson Jr W, Riley LW. Urban epidemic of severe leptospirosis in Brazil. Lancet 354: 820-825, 1999.

14. Levett PN. Leptospirosis: re-emerging or re-discovered disease?. Journal of Medical Microbiology 48: 417-418, 1999.

15. Ministério da Saúde. Sistema de Informação de Agravos de Notificação-SINAN. http://dtr2004.saude.gov.br/sinanweb (10/04/07), 2007.

16. Ministério do Trabalho e Emprego. Manual de Orientação da Relação Anual de Informações Sociais - RAIS: Ano-base 1999. Brasília, 1999.

17. Pereira MM. Leptospirose em áreas urbanas do município do Rio de Janeiro, Tese de mestrado, Instituto Oswaldo Cruz, Rio de Janeiro, RJ, 1985.

18. Pereira MM, Andrade J. Human leptospirosis in a slum area in the city of Rio de Janeiro, Brasil, a serological and epidemiological study. Memórias do Instituto Oswaldo Cruz 854: 47-52, 1990.

19. Porto LA. Elementos conceituais para a compreensão da ocorrência da leptospirose em Salvador. Revista do Instituto de Medicina Tropical de São Paulo 7:51, 1994.

20. Sakata EE, Yasuda PH, Romero EC, Silva MV, Lomar AV. Sorovares de Leptospira interrogans isolados de casos de leptospirose humana em São Paulo, Brasil. Revista do Instituto de Medicina Tropical de São Paulo 34: 217-221, 1992.

21. Sanders EJ, Rigau-Pérez JG, Smits HL, Deseda CC, Vorndam VA, Aye T, Spiegel RA, Weyant RS, Bragg SL. Increase of leptospirosis in dengue-negative patients after a hurricane in Puerto Rico. The American Journal of Tropical Medicine and Hygiene 61: 399-404, 1999.

22. Secretaria de Estado de Planejamento e de Ciência e Tecnologia/ Superintendência de Planejamento. Informações básicas de Mato Grosso do Sul 1999. Campo Grande. MS, 1999.

23. Tavares-Neto J, Andrade J, Hofer E, Oliveira GF, Couto Júnior A. Freqüência de aglutininas para leptospira observadas em habitantes de Uberaba, Minas Gerais. Revista da Sociedade Brasileira de Medicina Tropical 29: 55-58, 1996.

24. Vasconcelos LM, Cisalpino EO, Vieira MNR e Koury MC. Presença de aglutininas antileptospira em diferentes grupos profissionais na cidade de Londrina, Paraná. Revista da Sociedade Brasileira de Medicina Tropical 25: 251-255, 1992. 